\title{
Effects of Soy Protein and Casein Diets on Fecal Enzyme Activity and Histochemistry of Mucin of the Colon
}

\author{
Motoi Tamura, ${ }^{1, *}$ Kazuki Shinohara, ${ }^{1}$ and Katsumi Imaizumi ${ }^{2}$ \\ ${ }^{1}$ National Food Research Institute, Ministry of Agriculture, Forestry and \\ Fisheries, Tsukuba 305-8642, Japan \\ ${ }^{2}$ Division of Bioresource and Bioenvironmental Sciences, Kyushu University, \\ Fukuoka 812-8581, Japan
}

(Received December 22, 1999)

\begin{abstract}
Summary Protein affects many metabolic processes that are related to tissue growth. Effects of soy protein and casein diets on fecal enzyme activity and histochemistry of mucin of the colon were studied in the present experiments. Male mice were fed a soy protein or casein diet for one month (measurements by histochemistry) or for three weeks (measurements of fecal enzyme activity). Fecal $\beta$-glucosidase and $\beta$ glucuronidase activities were significantly higher in the mice fed the soy protein diet than in those fed the casein diet. There were significant differences in the histochemical morphology of the crypt of the colon

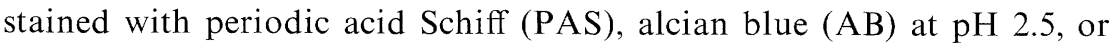
high iron diamine/alcian blue (HID/AB) at $\mathrm{pH} 2.5$ between the mice fed the casein and those given the soy protein one. Granules strongly stained with $\mathrm{PAS}$ and $\mathrm{AB}$ were more numerous in the area from the middle to the upper part of the crypts in the mice fed the casein diet. However, in the mice fed the soy protein diet, the granules strongly stained with PAS and $\mathrm{AB}$ were widely distributed in the area from the lower to the upper part of the crypts. The difference in the histochemical morphology of the colonic crypts observed in our experiment might have been caused by a difference in the metabolism of microflora, by a difference in polyamine catabolism by the microflora, or by a different rate of colonic proliferation between the mice fed the soy protein and those fed the casein. These factors might be compounded to account for the difference in the histochemical morphology of the colonic crypt between the two dietary groups.
\end{abstract}

Key Words: soy protein, casein, mucin histochemistry, fecal enzyme activity

* To whom correspondence should be addressed. 
Dietary protein has been found to affect lipid metabolism in both humans and experimental animals. Many investigators have reported that the serum cholesterol level in animals fed soy protein is significantly lower than that in animals fed casein [1-4]. It is reported that the cholesterol micelles containing soy protein peptic hydrolysate with bound phospholipids and soy protein peptic hydrolysate significantly suppressed cholesterol uptake by Caco-2 cells compared with the cholesterol micelles containing casein tryptic hydrolysate [5]. Feeding diets of the high-molecular-weight fraction after removal of water-soluble peptides from proteinase-treated soybean isolate raised fecal lipid and acidic steroid excretion to a greater extent than feeding casein diets [6]. Increasingly, soy bean products are being substituted for animal protein in the human diet. Protein affects many metabolic processes that are related to tissue growth. Luminal polyamines are important local factors for growth and development of cells in the small intestinal and colonic mucosa [7]. It is also reported that the proportion of polyamines that may be available for the metabolic demand of the large intestinal mucosal tissue is primarily of microbial origin rather than of dietary origin [8]. However, there is little information on the effects of the soy protein and casein diets on the fecal bacterial enzyme activity and the histochemistry of the colon. The present study was undertaken to investigate fecal bacterial enzyme activity and histochemical changes in the colon of mice fed a soy protein or casein diet.

\section{MATERIALS AND METHODS}

Animals and diets. Male mice of the Crj:CD-1 (ICR) strain (five weeks old) were obtained from Charles River Japan, Inc. (Kanagawa, Japan). The mice were randomly divided into two groups of five animals in each group (groups 1 and 2) used for histochemistry and into two groups of six animals in each (groups 3 and 4) used for measurements of fecal enzyme activity. The animals were housed individually in suspended stainless-steel cages with wire mesh bottoms, in a room kept at $24 \pm 0.5^{\circ} \mathrm{C}$ and a relative humidity of $65 \%$, with lighting consisting of alternating 12-h periods of light and darkness. The animals were fed a commercial non-purified diet (type MF, Oriental Yeast Co., Tokyo, Japan) given ad libitum for 14 months (groups 1 and 2), or for 11 months (groups 3 and 4). The MF diet was replaced with the casein (groups 1 and 3 ) or soy protein (groups 2 and 4 ) diets, and the mice were provided it and water ad libitum for one month (groups 1 and 2 ) or for three weeks (groups 3 and 4). In our preparatory experiment, we confirmed that there were no significant differences in the fecal $\beta$-glucosidase and $\beta$-glucuronidase activities between the mice fed the MF diet for 11 months and those fed the MF diet for 14 months. Moreover, it is reported that both $\beta$ glucosidase and $\beta$-glucuronidase activities are stable after the feeding of a diet for 7 days [9]. So, for the measurement of fecal enzyme activity, following the MF diet feeding for 11 months, the animals were fed the soy protein or casein diets for three weeks in groups 3 and 4 . The nitrogen sources of these diets were casein (Wako 
Table 1. Composition of experimental diets.

\begin{tabular}{lcc}
\hline Ingredient & Casein diet (\%) & Soy protein diet (\%) \\
\hline Casein & 20 & - \\
Soy protein & - & 20 \\
L-Methionine & 0.2 & 0.2 \\
Cornstarch & 45.8 & 45.8 \\
Sucrose & 18 & 18 \\
Corn oil & 5 & 5 \\
Cellulose powder & 5 & 5 \\
Vitamin mixture $^{\mathrm{a}}$ & 2 & 2 \\
Mineral mixture $^{\mathrm{b}}$ & 4 & 4 \\
\hline
\end{tabular}

${ }^{a}$ Obtained from Oriental Yeast Co. Composition (mg/ $\mathrm{kg}$ diet): retinol acetate, 3.44; cholecalciferol, $0.05 ; \alpha$-tocopheryl acetate, 100; menadione, 104; thiamin $\mathrm{HCl}, 24$; riboflavin, 80; pyridoxine $\cdot \mathrm{HCl}, 16$; cyanocobalamine, 0.01 ; ascorbic acid, 600; biotin, 0.4; folic acid, 4; calcium pantothenate, 100; $p$-aminobenzoic acid, 100; niacin, 120; inositol, 120; choline chloride, 4,000; and cellulose powder, 14,624. ${ }^{\mathrm{b}}$ Obtained from Oriental Yeast Co. Composition $(\mathrm{mg} / \mathrm{kg}$ diet): calcium phosphate, dibasic, 5,824; potassium phosphate, monobasic, 10,288; sodium phosphate, monobasic, 3,740; sodium chloride, 1,864; calcium lactate, 14,036; ferric citrate, 1,272; magnesium sulfate, 2,868; zinc carbonate, 44; manganese sulfate, 48; cupric sulfate, 12; and potassium iodide, 4.

Pure Chemical, Industries, Ltd., Osaka, Japan) or soybean protein isolates (Fujipro R, Fuji Oil Co., Osaka, Japan). The composition of each diet is shown in Table 1. Body weight and food consumption were measured. In the experiment on fecal enzyme activity, feces of mice were collected in the morning. At the end of the feeding trial, all mice were anesthetized with diethyl ether, and the colon were immediately removed for the histochemical studies.

Histochemical studies. After laparotomy of the colon, $10 \%$ formalin phosphate-buffered solution ( $\mathrm{pH} 7.3$ ) was injected into the intestinal lumen under low pressure. Portions from the middle of the colon were immediately removed. Small tissue slices were fixed for $24 \mathrm{~h}$ in cold $10 \%$ formalin, dehydrated in a graded ethanol series, passed through absolute ethanol and xylene, and embedded in paraffin. Serial 5- $\mu \mathrm{m}$ sections of the colon were cut and stained with periodic acid Schiff (PAS) with counterstaining of nuclei with Mayer's hematoxylin [10] or alcian blue $(\mathrm{AB}) \mathrm{pH} 2.5$ with counterstaining of nuclei with $0.1 \%$ Nuclear Fast Red in $5 \%$ aluminum sulfate [11]. Colonic sections were also stained with high iron diamine/alcian blue (HID/AB) pH 2.5 [12]. At least 20 sections were observed for each specimen. Each section was examined by light microscopy and photographed by using a Biophot VBS light microscope (Nikon Co., Ltd., Tokyo, Japan).

Sampling. In the morning of the final day of feeding the experimental diet, feces of mice were collected individually and frozen at $-40^{\circ} \mathrm{C}$ until measurement of fecal enzyme activity could be performed.

Measurement of enzyme activity. A $1: 100$ fecal suspension was prepared in pre-reduced $0.1 \mathrm{M}$ phosphate buffer $(\mathrm{pH} 7.0)$. Nonbacterial debris was removed by 
A

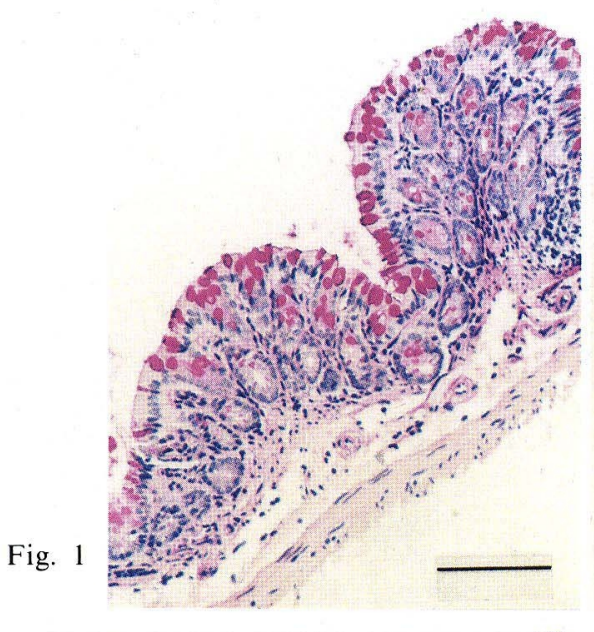

B

A

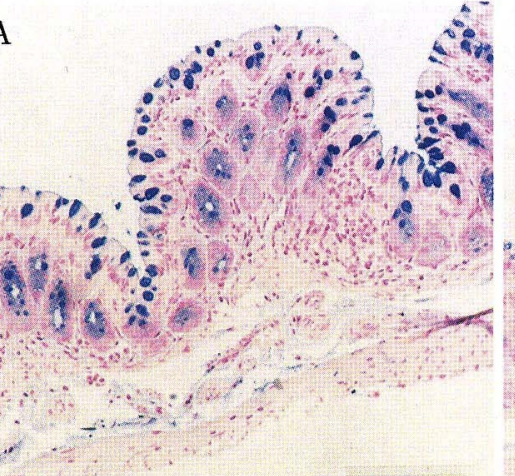

Fig. 2

$$
8
$$

B
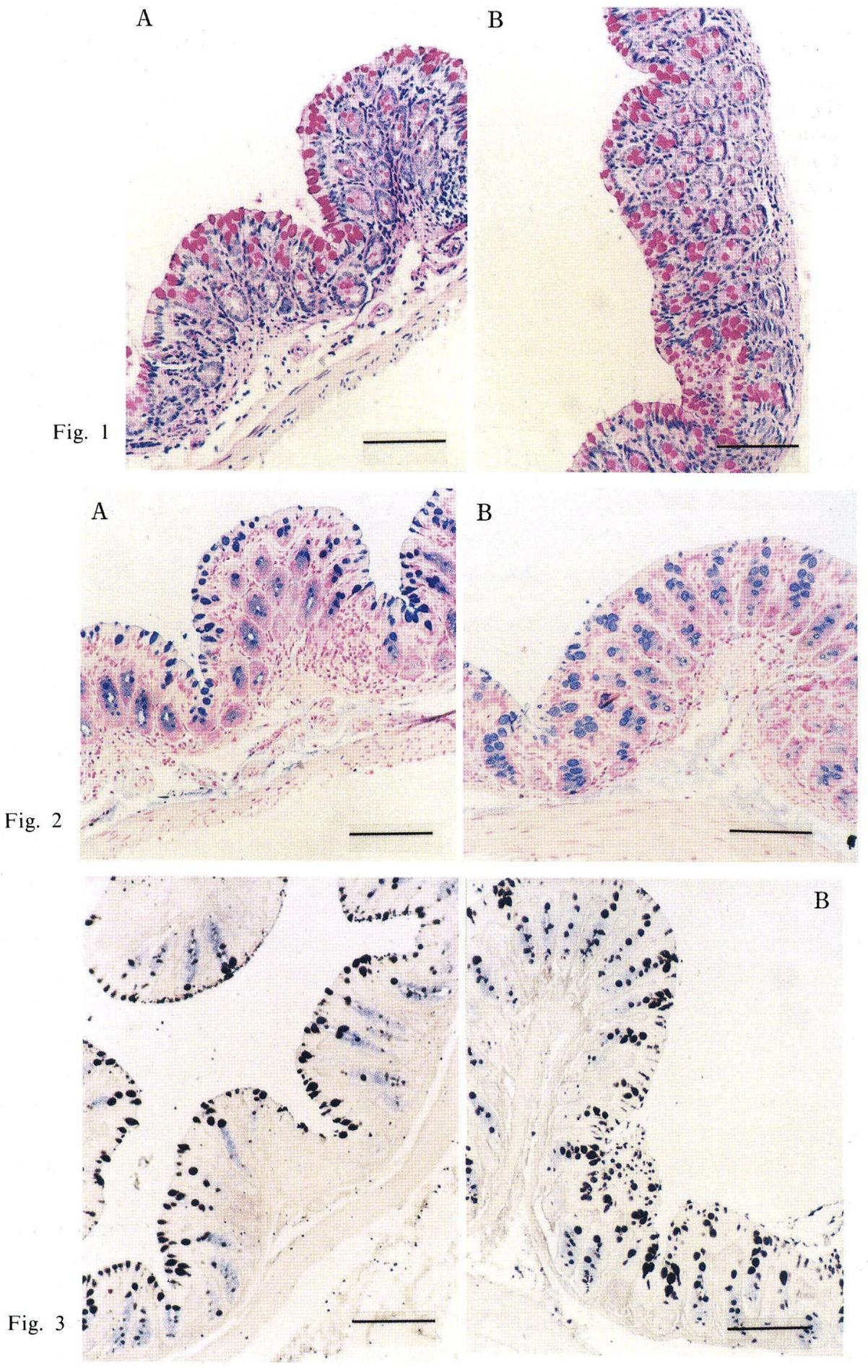

J. Clin. Biochem. Nutr. 
Table 2. Fecal enzyme activities $(\mu \mathrm{mol} / \mathrm{h} / \mathrm{g}$ feces $)$ of mice fed the casein or soy protein diet.

\begin{tabular}{lcc}
\hline Dietary group & $\beta$-Glucosidase activity & $\beta$-Glucuronidase activity \\
\hline Casein diet $(n=6)$ & $39.5+8.0$ & $136.5 \pm 34.8$ \\
Soy protein diet $(n=6)$ & $116.9 \pm 25.1^{*}$ & $369.4 \pm 95.8^{*}$ \\
\hline
\end{tabular}

Values are means \pm SEM. ${ }^{*}$ Significantly different $(p<0.05)$ from the casein diet group.

centrifugation at $700 \times g$ for $2 \mathrm{~min}$, and the supernatant fluids were used immediately for $\beta$-glucosidase and $\beta$-glucuronidase assays. $\beta$-Glucosidase activity was measured with $p$-nitrophenyl- $\beta$-D-glucopyranoside (Sigma, St. Louis, Mo., USA) as substrate; and $\beta$-glucuronidase activity, with $p$-nitrophenyl- $\beta$-Dglucuronide (Sigma). Enzyme activity was measured as previously described [13].

Statistics. $\quad \beta$-Glucosidase and $\beta$-glucuronidase activities were reported as the mean \pm SEM. Student's $t$-test was used to determine the statistical significance of the differences between mean values.

\section{RESULTS}

No significant differences in body weight $(\mathrm{g})$ between the mice fed the casein and soy protein diets were observed in either the experiment of fecal enzyme activity or the histochemical experiment. Also, there were no significant differences in the food consumption ( $\mathrm{g} / \mathrm{day}$ ) between the two diet groups in either type of the experiment. There were no significant differences in the quantity of feces produced per day between the mice fed the casein and those fed the soy protein.

\section{Fecal enzyme activity}

There were significant differences in fecal enzyme activities between the mice fed the casein and soy protein diets. Both $\beta$-glucosidase and $\beta$-glucuronidase activities were significantly higher in the mice fed the soy protein diet than in those fed the casein one (Table 2).

\section{Histochemical studies}

There were significant differences in the histochemical morphology of the crypt of the colon stained with PAS (Fig. 1), AB at pH 2.5 (Fig. 2), or HID/AB at $\mathrm{pH} 2.5$ (Fig. 3) between the two diet groups. The granules strongly stained with

Fig. 1. A: PAS staining of the middle of the colon of a mouse fed the casein diet (bar: 100 $\mu \mathrm{m}$ ). B: PAS staining of the middle of the colon of a mouse fed the soy protein diet (bar: $100 \mu \mathrm{m})$.

Fig. 2. $\mathrm{A}: \mathrm{AB} \mathrm{pH} 2.5$ staining of the middle of the colon of a mouse fed the casein diet (bar: $100 \mu \mathrm{m})$. B: AB pH 2.5 staining of the middle of the colon of a mouse fed the soy protein diet (bar: $100 \mu \mathrm{m}$ ).

Fig. 3. A: HID/AB pH 2.5 staining of the middle of the colon of a mouse fed the casein diet (bar: $100 \mu \mathrm{m}$ ). B: HID/AB pH 2.5 staining of the middle of the colon of a mouse fed the soy protein diet (bar: $100 \mu \mathrm{m}$ ).

Vol. 28, No. 1, 2000 
PAS and $\mathrm{AB}$ pH 2.5 were more numerous in the area from the middle to the upper part of the crypt in the mice fed the casein diet. However, in the mice fed the soy protein diet, the granules strongly stained with PAS and AB pH 2.5 were widely distributed in the area from the lower to the upper part of the crypt. This means that the mucosaccharides, including the acid material, were more concentrated in the area from the middle to the upper part of the crypt of the colon in the mice fed the casein diet. In contrast, the mucosaccharides were widely distributed throughout the crypt in the mice fed the soy protein diet. In the HID/AB pH 2.5 staining, the area stained with $\mathrm{AB}$ pH 2.5 was confined to the middle area of the crypt of the colon of mice fed either diet, indicating that sialomucins were mainly present in the middle area of the crypt of the colon in both groups. The granules stained black-brown (sulfomucin) were more numerous in the area from the middle to the upper part of the crypt and dominant in the surface area of the crypt of the colon in the mice fed the casein diet. In the mice fed the soy protein diet, however, these granules were found from the lower to the upper part of the crypt of the colon. In the surface area of the crypt, there were apparently fewer black-brown granules (sulfomucin) in the mice fed the soy protein diet than in the mice fed the casein diet. Thus, in the soy protein diet group, sulfomucin was widely distributed throughout the crypt of the colon, but, in the mice fed the casein diet, there was little sulfomucin in the lower site of the crypt of the colon.

\section{DISCUSSION}

There were significant differences in $\beta$-glucosidase and $\beta$-glucuronidase activities between the mice fed the soy protein and those given the casein diet. It is reported that a large variety of protein substrates are potentially available for digestion by bacteria in the colon [14]. The difference in floral enzyme activity might be caused by the difference in the dietary or endogenous protein that escapes digestion and absorption in the small intestine. The floral metabolism of mice fed the soy protein diet may have differed from that of the mice fed the casein diet. Some plant $\beta$-glycosides are changed to their aglycone by the action of $\beta$ glucosidase of the intestinal microflora and thereby became toxic. Bacterial $\beta$ glucuronidase is thought to hydrolyze glucuronide conjugates in the gut and to yield carcinogenic substances in rats [15]. Recent interest in food flavonoids has increased greatly because of the antioxidant and free radical-scavenging abilities associated with some phenolics and their potential effects on human health [16]. Many flavonoids occur in foods in the glycosidic form. So, the $\beta$-glucosidase of the microflora may be concerned in bioavailability by hydrolyzing the flavonoid glycoside to its aglycone. The soy isoflavone genistein has recently emerged as an important dietary component having many health-related and clinical benefits [ 17 , 18]. It is reported that genistein is present in the enterohepatic circulation [19]. A higher tendency of the floral $\beta$-glucuronidase activity in the soy protein diets may be useful for the genistein intake by hydrolyzing the bile excretory genistein- $\beta$ - 
glucuronide in the gut. There were significant changes in luminal polyamines in the colon between pigs fed soy protein and those fed casein, and the protein source reportedly did not affect the polyamine concentration either in the jejunum or in the ileum lumen. In the proximal colon, however, higher luminal concentrations of putrescine and cadaverine were observed with the casein diet, but the spermidine concentration remained higher with the soy protein diet. As the polyamine contents in the gut of conventional animals are highly influenced by the metabolic activity of intestinal flora [8], the difference in concentration of luminal polyamines between the two dietary groups might have been caused by a difference in floral metabolism between the two diet groups. It was reported that in an in vitro test for polyamine production by intestinal bacteria, many species of the genus Bacteroides synthesized mainly spermidine but no putrescine or cadaverine, and Fusobacteria formed a high amount of putrescine [8]. The difference of luminal polyamine in the colon [20] might be due to the changes of the floral composition of the animals fed different protein sources. It is reported that luminal polyamines are important local factors for the growth and development of cells in the intestinal and colonic mucosa [7]. It is also reported that the proportion of polyamines that may be available for the metabolic demand of the large intestinal mucosal tissue are primarily of microbial rather than of dietary origin [8]. Thus, the change of floral metabolism between the mice fed the soy protein and casein diets might affect the colonic function by changing the luminal polyamine metabolism between the two dietary groups. In our experiment, there were significant histochemical differences in the colon between the two dietary groups. In the soy protein diet group, sulfomucin was widely distributed from the lower to the upper part of the crypt of the colon. In contrast, in the casein diet group sulfomucin was distributed from the middle to the upper part of the crypt and was dominant in the surface area of the colon. It is reported that migration of cells to the colonic surface produces not only morphological changes but also changes in the chemical composition of the mucins produced [21]. It was also reported in one study that all the patients having colon carcinoma showed definite abnormalities in their mucosa [22]. From these reports, the mucin profile of the crypt of the colon differs according to the stage of maturation and the malignancy status. It is reported that the colonic epithelium proliferated more in the mice fed a soy protein diet than in those fed a casein one [23]. The differences in histochemical profiles of the crypt of the colon between the mice fed the soy protein and casein diets, as observed in our experiment, might be related to the different rate of colonic proliferation between the two dietary groups. It is reported that, in the absence of a colonizing microflora, the crypt mucin becomes more and more sulfated. The sulfation "off" switch in the colonic crypt seems to be sensitive to the presence of one or more members of the normal microflora of the colon [24]. Colonizing microflora in the lower colonic crypt also may affect the histochemical morphology of the colonic crypt. The difference of the histochemical morphology of the colonic crypt observed in our experiment might be caused by the difference of metabolism of

Vol. 28, No. 1, 2000 
microflora, by the difference of polyamine production catabolized by the microflora, or by the different rate of colonic proliferation between the mice fed the soy protein and casein diets. These factors might be compounded to account for the difference in histochemical morphology of the colonic crypt between the two dietary groups.

\section{REFERENCES}

1. Kritchevsky, D. (1979): Vegetable protein and atherosclerosis. J. Am. Oil Chem. Soc., 56, $135-140$.

2. Huff, M.W., and Carroll, K.K. (1980): Effects of dietary protein on turnover, oxidation and absorption of cholesterol, and on steroid excretion in rabbits. J. Lipid Res., 21, 546-558.

3. Kritchevsky, D., Tepper, S.A., and Klurfeld, D.M. (1987): Dietary protein and atherosclerosis. J. Am. Oil Chem. Soc., 64, 1167-1171.

4. Nagata, Y., Tanaka, K., and Sugano, M. (1981): Further studies on the hypocholesterolaemic effect of soya-bean protein in rats. Br. J. Nutr., 45, 233-241.

5. Nagaoka, S., Miwa, K., Eto, M., Kuzuya, Y., Hori, G., and Yamamoto, K. (1999): Soy protein peptic hydrolysate with bound phospholipids decreases micellar solubility and cholesterol absorption in rats and caco-2 cells. J. Nutr., 129, 1725-1730.

6. Azuma, N., Kanaya, M., Kanamoto, R., and Iwami, K. (1999): Feeding soybean resistant protein to rats raises fecal bile acid excretion but counteracts a deoxycholate-caused decrease in colonic aberrant crypt foci. J. Nutr. Sci. Vitaminol., 45, 183-192.

7. Loser, C., Eisel, A., Harms, D., and Folsch, U.R. (1999): Dietary polyamines are essential luminal growth factors for small intestinal and colonic mucosal growth and development. Gut, 44, 12-16.

8. Noack, J., Kleessen, B., Proll, J., Dongowski, G., and Blaut, M. (1998): Dietary guar gum and pectin stimulate intestinal microbial polyamine synthesis in rats. J. Nutr., 128, 13851391.

9. Tamura, M., Hirayama, K., and Itoh, K. (1996): Comparison of colonic bacterial enzymes in gnotobiotic mice monoassociated with different intestinal bacteria. Microb. Ecol. Health Dis., 9, 287-294.

10. McManus, J.F. (1946): Histological demonstration of mucin after periodic acid. Nature, 158, 202.

11. Spicer, S.S. (1967): Histochemistry of connective tissue mucopolysaccharides, in The Connective Tissue, ed. by Wanger, B.M., and Smith, D.E., Williams \& Wilkins Co., Baltimore, pp. 251-303.

12. Spicer, S.S. (1965): Diamine methods for differentiating mucosubstances histochemically. $J$. Histochem. Cytochem., 13, 211-234.

13. Rowland, I.R., Mallett, A.K., and Wise, A. (1983): A comparison of the activity of five microbial enzymes in cecal content from rats, mice, and hamsters, and response to dietary pectin. Toxicol. Appl. Pharmacol., 69, 143-148.

14. Cummings, J.H., and Macfarlane, G.T. (1991): The control and consequences of bacterial fermentation in the human colon. J. Appl. Bacteriol., 70, 443-459.

15. Goldin, B.R., and Gorbach, S.L. (1975): The relationship between diet and rat fecal bacterial enzymes implicated in colon cancer. J. Natl. Cancer Inst., 57, 371-375.

16. Bravo, L. (1998): Polyphenols: Chemistry, dietary sources, metabolism, and nutritional significance. Nutr. Rev., 56, 317-333.

17. Steele, V.E., Pereira, M.A., Sigman, C.C., and Kelloff, G.J. (1995): Cancer chemoprevention agent development strategies for genistein. J. Nutr., 125, 713S-716S.

18. Barnes, S. (1995): Effect of genistein on in vitro and in vivo models of cancer. J. Nutr., 125, $777 \mathrm{~S}-783 \mathrm{~S}$. 
19. Sfakianos, J., Coward, L., Kirk, M., and Barnes, S. (1997): Intestinal uptake and biliary excretion of the isoflavone genistein in rats. J. Nutr., 127, 1260-1268.

20. Benamouzig, R., Mahé, S., Meziani, K., Martin, A., Juste, C., Catala, I., and Tomé, D. (1999): Effects of soy protein diet on digestive lumenal polyamines and colonic cell proliferation in pigs. Reprod. Nutr. Dev., 39, 213-221.

21. Specian, R.D., and Oliver, M.G. (1991): Functional biology of intestinal goblet cells. Am. J. Physiol., 260, C183-C193.

22. Shamsuddin, A.K., Weiss, L., Phelps, P.C., and Trump, B.F. (1981): Colon epithelium. IV. Human colon carcinogenesis. Changes in human colon mucosa adjacent to and remote from carcinomas of the colon. J. Natl. Cancer Inst., 66, 413-419.

23. Govers, M.J.A.P., Lapré, J.A., De Vries, H.T., and Van der Meer, R. (1993): Dietary soybean protein compared with casein damages colonic epithelium and stimulates colonic epithelial proliferation in rats. J. Nutr., 123, 1709-1713.

24. Hill, R.R.H., Cowley, H.M., and Andremont, A. (1990): Influence of colonizing micro-flora on the mucin histochemistry of the neonatal mouse colon. Histochem. J., 22, 102-105. 